\title{
Outras vozes, outros arquivos. A memória escrita das classes subalternas ${ }^{1}$
}

Other voices, other files. The written memory of the subaltern classes

Otras voces, otros archivos. La memoria escrita de las clases subalternas

\author{
Antonio Castillo Gómez \\ Universidad de Alcalá (Espanha) \\ https://orcid.org/0000-0002-7113-7931 \\ antonio.castillo@uah.es
}

\section{Resumo}

Este artigo reflete sobre a capacidade de produzir testemunhos escritos pelas classes subalternas. A partir de uma aproximação diacrônica, indaga as particularidades de tal memória ao longo do tempo. Distingue entre a conservação indireta e fragmentária típica dos séculos anteriores ao XIX, geralmente depositada em vestígios isolados, e outra de um tipo mais denso e articulado desenvolvido na era contemporânea, especialmente no século XX. Nesse sentido, uma parte do artigo se ocupa das recentes iniciativas de salvaguarda da memória escrita das classes subalternas. Analisa os chamados "arquivos à margem" e, em particular, o que significam "arquivos da escrita popular" no campo dos arquivos pessoais. Por último, o próprio conceito de "arquivo" é problematizado.

Palavras-chave: Memória escrita. Classes subalternas. Arquivos à margem. Arquivos pessoais. Arquivos de escrita populares.

\footnotetext{
${ }^{1}$ Este artigo foi realizado como um produto do Projeto de Investigação Vox populi. Espacios, prácticas y estrategias de visibilidad de las escrituras del margen en las épocas Moderna y Contemporánea (PID2019107881GB-I00), financiado pelo Ministério de Ciência e Inovação e pela Agência Estatal de Investigação do Governo de Espanha. Meus agradecimentos a José I. Monteagudo Robledo e Fabio Caffarena por sua atenta leitura e observações de melhoria do texto. Versão em portugués de Dóris Bittencourt Almeida e Carolina Llanes. E-mail: almeida.doris@gmail.com; carolgllanes@gmail.com.
} 


\begin{abstract}
This article reflects on the capacity to produce testimonies written by the subaltern classes. From a diachronic approach, he investigates the particularities of such memory over time. It is distinguished between the indirect and fragmentary conservation typical of the pre-nineteenth centuries, usually deposited in isolated remains, and another of a denser and articulated type developed in the contemporary era, especially in the twentieth century. It analyzes so-called "marginal archives" and, in particular, what "popular writing archives" mean in the field of personal archives or auto-archives. Finally, the very concept of "archives" is problematized.
\end{abstract}

Keywords: Written memory. Subaltern classes. Marginal archives. Personal archives. Popular writing archives.

\title{
Resumen
}

El presente artículo reflexiona sobre la capacidad de producir testimonio escrito por parte de las clases subalternas. Desde un acercamiento diacrónico indaga en las particularidades de dicha memoria a lo largo del tiempo. Se distingue entre la conservación indirecta y fragmentaria propia de los siglos anteriores al XIX, depositada por lo común en vestigios aislados, y otra de tipo más denso y articulado desarrollada en la época contemporánea, especialmente en el siglo XX. En relación con esto una parte del artículo se ocupa de las recientes iniciativas de salvaguarda de la memoria escrita de las clases subalternas. Analiza los denominados «archivos del margen» y, en particular, lo que suponen los «archivos de la escritura popular» en el campo de los archivos personales o del yo. Por último, se problematiza el concepto mismo de «archivo».

Palabras clave: Memoria escrita. Clases subalternas. Archivos del margen. Archivos personales. Archivos de la escritura popular. 
ocorre que o passado é sempre uma morada mas não existe esquecimento capaz de demoli-lo ${ }^{2}$

\section{O resgate dos subalternos}

Em um poema inesquecível e largamente citado, escrito no longo exílio de Bertold Brecht, a partir da chegada de Hitler ao poder em 1933, o poeta e dramaturgo alemão nos leva ao pensamento do trabalhador que assiste, estupefato, as escassas menções a seus iguais nas narrativas do passado. São trabalhadores que participaram da construção de algum monumento da Antiguidade, tais como, as pirâmides egípcias, os templos incas, a grande Muralha da China ou dos soldados que combateram e deram sua vida em mil batalhas, desde a conquista da Índia por Alexandre Magno, até a vitória de Frederico II na Guerra dos Sete Anos. Não é casualidade que muitas dessas pessoas ficaram excluídas e esquecidas atrás dos grandes nomes, majoritariamente homens, que têm hegemonizado e, às vezes, seguem hegemonizando a escrita histórica e a memória social.

Se o poema que acabo de fazer referência, "Perguntas de um trabalhador diante de um livro", foi escrito por Brecht em 1934 para o livro Kalendergeschichten, cinco anos depois, compôs outro igualmente crítico, "A literatura será objeto de investigação", em que condenou aqueles que "se sentaram em cadeiras de ouro para escrever". Propôs, em contrapartida, que "literaturas inteiras, escritas em seletas expressões", fossem examinadas, a fim de "encontrar indícios de que também houve resistência, onde havia opressão", aplaudindo, para terminar, o gesto de quem "se uniu aos de baixo" e narrou suas vidas "com arte, na nobre linguagem antes reservada à glorificação dos reis” (BRECHT, 1998, p.91-92, 127-129).

Nesses poemas, Bertold Brecht aponta algumas das contradições que, social e academicamente, podemos incorrer quando, por ação ou por omissão, colaboramos para que se eternize o silêncio dos de baixo, se mascare seu protagonismo no acontecer histórico, se elimine sua história, ou melhor, se dilua em outros ditos pelos de cima ou nos termos mais propícios para estes, sendo este o erro que reproduz toda a periodização histórica assentada em nações e reinados.

Nessa perspectiva, o descobrimento das classes populares como sujeitos da história aflora na segunda metade do século XIX: por um lado, Marx propôs que a história se entenderia como a história da sociedade, incluindo todos os âmbitos da atividade humana; por outro, um historiador como Jules Michelet situou as pessoas comuns no centro do cenário revolucionário, enquanto John Richard Green foi autor de uma história do povo inglês, mas não de seus reis e conquistadores.

Naqueles tempos, a ideia de povo esteve muitas vezes envolta em uma aura de romantismo, desprovida da conotação política própria das primeiras décadas do novecentos, quando também Antonio Gramsci refletiu acerca dos subalternos em seus Cadernos do Cárcere, escritos entre 1929 e 1935, e nas cartas que escreveu na prisão. Segundo Guido Liguori, este conceito tem três acepções na obra do pensador italiano. Inicialmente, o utiliza para definir os oficiais subalternos do exército, depois, a partir do Caderno 3, para referir-se às classes subalternas em oposição à classe dominante e, por último, considera uma dimensão cultural (LigUORI, 2011). Para Gramsci, os grupos subalternos seriam aqueles que, em cada momento, foram marginalizados do poder político, econômico, ideológico ou cultural,

\footnotetext{
${ }^{2}$ BenEdETtI Mario, «Olvidadores», em El olvido está lleno de memoria, Madrid, Visor, 1997 (1995, 1ª ed.), p.17.
} 
retirados, habitualmente, por aqueles que exercem a "hegemonia", isto é, a classe dominante, que, para o intelectual italiano, é sempre uma, enquanto que as classes subalternas são mais de uma. Em suas palavras, "a história dos grupos sociais subalternos é necessariamente desprezada e episódica"; e, por consequência, "as classes subalternas, por definição, não são unificadas e não podem se unificar até que possam ser legitimadas pelo Estado: sua história, portanto, está entrelaçada com a da sociedade civil, é uma função desintegrada e descontínua da história da sociedade civil"'3.

Nessa sequência, caberia perguntar, como fez há alguns anos Gayatri Spivak, se os sujeitos subalternos podem falar por si mesmos. A resposta da pensadora indiana, estudiosa de crítica literária e literatura, é decepcionante. Especialista na corrente dos estudos pós-coloniais, argumentou sobre as dificuldades de encontrar essa própria voz, apoiando-se no etnocentrismo, a partir do qual tem estudado e interpretado muitas culturas distantes dos cânones ilustrados do mundo ocidental (SPIVAK, 1999). ${ }^{4}$ Além de realçar os sujeitos subalternos que não estão apenas em países descolonizados, suas teses, mais que polêmicas, são abertamente discutíveis porque negam aos subalternos a capacidade de falarem e produzirem testemunhos por si mesmos, já que ao fazê-lo, segundo ela, perdem essa condição ${ }^{5}$.

Existem muitas vozes e testemunhos mediados, em que são outros que falam em nome das classes subalternas, mas, igualmente, ao longo da história, se podem encontrar numerosas ocasiões que produziram testemunhos escritos próprios. Desde uma perspectiva marxista, nos anos sessenta e setenta, varios historiadores britânicos, expoentes da história vista de baixo (THOMPSON, 1996), incluíram cartas ameaçadoras de campesinos e operários em algumas investigações. Eric Hobsbawm e Georges Rudé se valeram, de forma pontual, de algumas cartas desse tipo, assinadas pelo mítico Capitão Swing, que os campesinos enviaram aos proprietários rurais durante as revoltas agrárias na Inglaterra, em 1830 (HOBSBAWM, RUDÉ, 1968). Por sua vez, Edward P. Thompson investigou, com maior profundidade, testemunhos similares em seus trabalhos acerca dos protestos campesinos e proletários ingleses do século XVIII e do primeiro terço do XIX (THOMPSON, 1977). Isso não foi obstáculo para o mesmo Hobsbawn aludir, pouco depois, a dificuldade que havia em conhecer o pensamento dos de baixo, a partir de seus próprios testemunhos e não de suas ações, dado que "a maior parte do passado as pessoas eram geralmente analfabetas de qualquer maneira" (HOBSBAWM, 1985, p.97).

Sem dúvida que é assim, como o paleógrafo Armando Petrucci havia advertido anteriormente ao apontar que, mesmo em uma sociedade de amplo desenvolvimento da alfabetização, como a industrializada do mundo contemporâneo, o "uso global e contínuo da cultura escrita, ou seja, a capacidade de escrever (compor corretamente um conjunto de textos) e de ler (compreender) uma gama mais ampla de textos, é limitada a uma elite muito restrita da população, pertencente à classe média alta" (PETRUCCI, 1978, p.41). Entretanto, ao mesmo tempo que constatou esta realidade, fruto do desigual acesso social ao exercício da cultura escrita ao longo dos séculos, também assinalou a urgência da busca e do estudo da produção escrita das classes subalternas, fragmentária e dispersa nos períodos anteriores ao século XIX e mais densa e continuada durante a época contemporânea, como prova a ampla difusão da prática epistolar, do gênero memorialista ou da escritura doméstica e laboral.

\footnotetext{
${ }^{3}$ GRAMSCI, Antonio, Quaderni del carcere, 3, Quaderni 12-29, edição crítica do Instituto Gramsci aos cuidados de Valentino Gerratana, Torino, Einaudi, 1975, p. 2283 (=Quaderno 25, § 2) y 2288 (= Quaderno 25, § 5).

${ }^{4}$ Sobre esta nota pode-se consultar o estudo previo do tradutor ASENSI, 2009.

${ }^{5}$ A respeito disso é muito pertinente a crítica feita por PIEDRAS MONROY, Pedro Andrés, «Sobre Can the Subalterns's Speak de Gayatri Spivak», que pode ser lida em: https://www.academia.edu/9687318/Sobre_Can_the_Subaltern_Speak_de_Gayatri_Spivak. Acesso em 01/09/2021.
} 
Como diria, uns anos depois, a historiadora francesa Arlette Farge em seu "O sabor do Arquivo" (1989), "as classes populares, menos hábeis para manejar o escrito, nem por isso viveram sem representar-se a si mesmas: o arquivo possui recursos neste terreno, há que esforçar-se para buscá-los" (FARGE, 1991, p.79). Natalie Zemon Davis, por exemplo, nos explicou, faz tempo, sobre a força narrativa das súplicas de perdão dirigidas pelas pessoas comuns ao rei francês durante o século XVI. Com efeito, naqueles tempos, um dos recursos que oferece o arquivo para a memória escrita das classes subalternas está nas petições que seus membros dirigiram aos governantes e instituições para obter alguma graça, sobretudo porque, para eles, o relato de suas vidas e o esboço de distintas estratégias narrativas tinha o objetivo de convencer ou comover o destinatário da súplica (DAVIS, 1987).

Cabe destacar que que não se trata de sacralizar o valor dos testemunhos escritos das classes subalternas. Sua produção escrita possui fragilidades e parcialidades que qualquer outro documento também possui, apesar de encontrar-se, muitas vezes, descontextualizada. Sua qualidade testemunhal está nas mãos da capacidade interpretativa do historiador ou estudioso que trabalhe com ela, ao aproximar-se do passado, em qualquer de suas vertentes (social, política, cultural, religiosa, educativa ou lingüística). Mas essas dúvidas afetam igualmente a memória escrita das classes hegemônicas e nem sempre se colocam tão manifestamente como alguns o fazem, com respeito aos escritos das pessoas comuns.

\section{Os silêncios dos arquivos}

Ignorados pela historiografia, inclusive pela marxista que tem dado maior relevância ao estudo dos aparelhos do poder político e sindical dos trabalhadores, e frequentemente também pelas práticas do arquivo, que têm privilegiado e seguem privilegiando a conservação institucional e das elites, o testemunho escrito das classes subalternas comumente envolve estes indivíduos tão cheios de memória que Mario Benedetti evocou em alguns de seus poemas. Como em Te acordás hermano, no qual o autor se manifesta contra a marginalização do povo, inclusive por aqueles que assumem sua representação política ou pelos historiadores que marginalizam seu testemunho:

por outra parte nas obras mais eruditas

dos historiadores de ofício

o povo continua aparecendo nas notas de rodapé

e no última página da bibliografia. ${ }^{6}$

Mais que rastrear as palavras e signos silenciados, negados através dos "sintomas que a lógica da negação deixa como resíduos na ordem do discurso dominante" (MEZZADRA, 2008, p.28), trata-se de resgatar, conservar, arquivar e estudar o próprio testemunho escrito das pessoas comuns. Uma breve revisão sobre o acontecimento da escrita serve para constatar que esta tem sido, durante milênios, prerrogativa das classes dominantes, e, preferencialmente, dos homens, o que traz consigo numerosas exclusões: classes populares, mulheres, minorias (étnicas, religiosas, sexuais, etc.). Por isso mesmo, revisar as transformações da atividade escrita através do tempo supõe adquirir consciência do poder da escrita e do arquivo, e, por conseqüência, das sombras que cercam sua história, que afetam os testemunhos produzidos e legados pelas classes subalternas. Assunto que nos leva também a

\footnotetext{
${ }^{6}$ Por outro lado, nas obras mais eruditas, dos historiadores de ofício, a cidade ainda aparece nas notas de rodapé e na última seção da bibliografia. BENEDETTI Mario, «Te acordás hermano», in Mario Benedetti, El olvido está lleno de memoria, op. cit. p. 43
} 
refletir sobre a própria história dos arquivos. Estes geralmente guardam incontáveis arquivos de documentação associados ao desempenho do poder, seja do Estado, da Igreja, das instituições, da família ou, inclusive, de indivíduos que tendem a perpetuar um certo elitismo documental. Como apontaram Joan M. Schwartz e Terry Cook, "os arquivos - como registros - exercem poder sobre a forma e direção da história, memória coletiva e identidade nacional, permitindo que nos conheçamos como indivíduos, grupos e sociedades". Complementam que este poder não escapa ao desempenho profissional dos arquivistas que, longe de ser neutro ou objetivo, como geralmente pretendem, envolve decisões que intervém ativamente na natureza, salvaguarda e ordenação dos fundos arquivísticos e, portanto, na memória da sociedade (SCHWARTZ, 2002, p.2-3).

Neste sentido, é pertinente lembrar também umas palavras de Jacques Le Goff. Em um texto, do ano de 1978, "Documento/ monumento", publicado na Enciclopedia Einaudi, o medievalista francês apontou que "o documento não é uma mercadoria ancorada no passado", mas "um produto da sociedade que o fabricou, segundo os vínculos de forças que nela retinha poder" (LE GOFF, 1991, p.236) Escreveu também que "o documento não é inócuo", senão o resultado de "uma montagem, consciente ou inconsciente, da história, da época, da sociedade que o produziu, mas, igualmente, das épocas posteriores, durante as quais continuou vivendo, talvez esquecido, durante as quais continuou sendo manipulado, apesar do silêncio" (LE GOFF, 1991, p.238).

Essas reflexões de Le Goff devem servir como um estímulo quando nos interessamos pela história da produção e conservação dos documentos. Não me compete entrar agora neste assunto, mas sim direi que algumas das linhas que tenho transitado concentram-se, preferencialmente, no relato institucional de arquivos e depósitos documentais, em seus fundos e em sua organização interna; cabe dizer que nem sempre se tem problematizado a natureza dos arquivos, nem mesmo seus preconceitos que introduzem ao reconhecimento deste estranho país que é o passado, desde o mais longínquo ao mais próximo. Enfrentamos, assim, um autêntico "conflito de arquivo", entendido como o que se desenvolve entre a documentação escrita selecionada e transmitida e aquela outra preterida, destruída ou desprezada, marginalizada por não servir aos interesses dos poderosos e às formas de fazer história hegemônica de cada tempo.

Essas questões também podem ser estendidas ao conceito arquivístico de arquivos familiares, em muitos casos claramente identificados às elites. De acordo com Olga Gallego Domínguez, os arquivos pessoais "compreendem tanto os das antigas famílias nobres, como os dos intelectuais, escritores, artistas, homens de Estado, políticos, militares, membros de igrejas, jornalistas, trabalhadores, profissionais etc., que têm produzido e conservado documentação de suas atividades" (GALLEGO DOMÍNGUEZ, 1993, p.17). Pode ser que a menção aos trabalhadores e o etecetera final tenham deixado resquícios das pessoas "sem atributos", mas estas não se mencionam explicitamente. Todavia, mais excludente é a proposta que, poucos anos depois, ofereceu Vicente Pons Alós, que considerou arquivos pessoais os "que agrupam a documentação relacionada a si mesmo ou às posições ocupadas por uma importante personagem e sua trajetória cultural, eclesiástica, social ou econômica" (PONS ALÓS, 1996, p.45) Muito diferente, no entanto, é a perspectiva adotada pelo historiador Philippe Artières e o sociólogo Jean-François Laé no livro Archives personalles, Histoire, Anthropologie et Sociologie. De acordo com os desafios abertos pela História Social da Escrita, sua proposta comporta com maior flexibilidade o termo "arquivos pessoais", de modo que estes se configuram tanto pelos escritos próprios de cada pessoa correspondências, agendas, diários, memórias, etc. - como por aqueles outros de caráter oficial - causas de divórcio, declarações de herdeiros, etc, - que permitem escrever a vida de um indivíduo e inclusive pensar como cada um "escreve" (ou ajuda a escrever) a sua vida em função dos documentos que produz, conserva e destrói (ARTIËRES, LAÉ 2011). 
Conforme as abordagens que têm regido boa parte da prática arquivística ao longo do tempo, a memória escrita preservada pode ser um melhor espelho da estrutura de poder e dos preconceitos estabelecidos em cada época. Paul Thompson chegou a estas conclusões após refletir sobre as presenças e ausências detectadas na correspondência privada conservada nos arquivos provinciais ingleses: significativa em termos de cartas cruzadas entre os proprietários de terras, mas quase inexistente em relação às trocas epistolares das pessoas comuns (THOMPSON, 1984, p.54). Suas deduções são igualmente válidas para outros lugares onde o processo de seleção se viu dificultado por argumentações que sempre favoreceram a memória institucional, de poder e das classes dirigentes. Como destacou Petrucci, "o domínio da memória e do esquecimento enquanto prática social é um fato eminentemente político e constitui um elemento fundamental de controle e de governo de uma sociedade desenvolvida" (PETRUCCI, 2002, p.116).

$\mathrm{O}$ assunto, naturalmente, permitiria reflexões mais profundas, mas não se podem ignorar que estas questões estão presentes na razão fundadora de alguns dos grandes arquivos históricos; como também que boa parte das políticas de destruição e expurgos, por um lado, e os projetos de difusão, por outro, hoje em dia digitalizados, tendem a priorizar feitos e pessoas ancorados numa visão estatal e institucionalista do devir histórico. Isto, em si mesmo, culmina em uma história hegemonizada pelas classes dirigentes, uma vez que estas têm sido, tradicionalmente, as que se apropriaram do Estado para interpretá-lo e usufruí-lo em seu próprio benefício corporativo, também quando este é resultado de revoluções em nome dos de baixo.

\section{Contra o esquecimento}

Uma maneira para que a história dos de baixo não seja roubada ou adornada pela apropriação que se faz dela em outros setores da sociedade, inclusive em determinados círculos acadêmicos, está na significação que, como historiadores, oferecemos à sua própria memoria documental. Interessa, pois, preservar o testemunho direto das classes populares para que não fiquem restritas a notas de rodapé dos livros de história, como denunciava o poema de Benedetti já citado, também para que a história não precise depender das visões transmitidas nas crônicas, relatos e informes, emanados pelos de cima.

Como apontado anteriormente, no que se refere à Idade Moderna, uma parte notável dos vestígios escritos da gente comum se arquivou em registros judiciais e policiais, como bem nos mostrou Arlette Farge em diferentes trabalhos. Suas investigações nesses fundos oitocentistas da polícia francesa têm resultado em uma série de obras que, além de aproximarse da vida das pessoas de Paris naqueles tempos, têm resgatado e integrado no laboratorio da história, os documentos pessoais das pessoas comuns, e também os de outra natureza, recuperando suas vozes, que estiveram esquecidas nesses tipos documentais (FARGE, 1979, 1986, 2003, 2007, 2009, 2019). Além de sustentar outra forma de fazer história, o exemplo desta historiadora, como também o de outros colegas de profissão, igualmente sensíveis à palavra dos de baixo, põem em relevo que, inclusive nos tempos passados, se podem encontrar testemunhos escritos das classes subalternas, apesar da escrita estar menos difundida nesses setores e que, salvo contadas exceções, tampouco desenvolveram uma mentalidade de conservação do escrito em nível pessoal ou familiar (PETRUCCI, 1995). 
Se, para o Ancien Régime francês, os fundos policiais dos Arquivos da Bastilha, custodiados pela Bibliothèque del'Arsenal, têm se revelado como explêndidos depósitos, em que se podem localizar evidências escritas de muitas vidas infames (FARGE; FOUCAULT, 1982; DUTRAY-LECOIN, MUZERELLE, 2010), como disse Foucault (1977), para o âmbito hispânico da Idade Moderna essas evidências escritas também podem ser observadas nos arquivos inquisitoriais e judiciais, civis e eclesiásticos. Nos processos instruídos por essas instâncias, durante os séculos XVI ao XVIII, era comum incorporar nos arquivos, como prova, documentos apreendidos dos indivíduos indiciados. Por exemplo, boa parte das cartas das pessoas comuns, que se têm conservado em nossos arquivos públicos, são encontradas precisamente nesses fundos ${ }^{7}$ (SÁNCHEZ RUBIO, TESTÓN NUÑEZ, 1989; MARTÍNEZ MARTÍNEZ, 2007), como também em outros relacionados com a emigração para a América, sejam los expedientes de bienes de difuntos, instados para a distribuição de heranças, sejam cartas em favor de parentes residentes na Pensínsula (OTTE, 1976; MACIAS, MORALES PADRÓN, 1991). Ademais, ali, em que o direito estabelecia a transmissão patrimonial em mãos do primogênito, como na Catalunha, os arquivos familiares construídos ao longo dos séculos conservam um amplo número de escrituras pessoais da Idade Moderna: livros de contas, livros de memórias, livros de família e correspondências. Alguns deles são próprios das elites urbanas e outros de campesinos, mais ou menos abastados ${ }^{8}$ (TORRES I SANS, 2000; CASTILLO GÓMEZ, 2006; JANÉ, POUJADE, 2015).

O panorama muda significativamente quando adentramos na época contemporânea. De um lado, o crescimento da alfabetização, a partir de meados do século XIX, ainda que desigual, em seu ritmo segundo os países (VINCENT, 2000), estabeleceu as bases para uma massiva apropriação da escrita pelas classes populares (LYONS, 2007; LYONS, 2013; EDLUND, ASHPLANT, KUISMIN, 2016), fazendo-se efetiva essa conquista do alfabetizado, que vinha acontecendo desde muito tempo atrás (CASTILLO GÓMEZ, 2002). De outro, muitas dessas escritas ainda se conservam em nível familiar, considerando seu valor testemunhal e emotivo; outras estão depositadas em diferentes arquivos, pois também, como no caso da Idade Moderna, em muitas circunstâncias serviram como prova em procesos judiciais e administrativos, como se manifestam nas obras de Verónica Sierra Blas (2009, 2016) ${ }^{9}$. Enfim, um terceiro conjunto é constituido por documentos que integram acervos nascidos expresssamente com o propósito de recuperar e conservar uma memória por si mesma frágil, suscetível de desaparecer, conforme se sucedem as gerações e se dispersam os patrimônios familiares.

A ideia da preservação do patrimônio pessoal autobiográfico remonta pelo menos a 1831, com a criação, na Finlândia, da Finnish Litterature Society, cujo objetivo era fomentar a literatura filandesa. Mais adiante, no começo do século XX, os sociólogos William Thomas y Florian Znanieckil levaram a cabo uma busca intensa de cartas em suas investigações sobre o campesinato polaco. Segundo o testemunho do proprio Thomas, começaram a amadurecer a ideia após encontrar no lixo a carta de uma imigrante polaca dirigida a seu pai. Pouco depois, em 1914, conseguiram que lhes cedessem uma grande quantidade de correspondências recebidas na redação de uma revista sobre folclore da Polônia. Com esse material inicial e com a colaboração de Znaniecki, publicaram um anúncio em um periódico de Chicago com o objetivo de conseguirem a correspondência recebida nos Estados Unidos pelos numerosos polacos que haviam chegado ali em diferentes levas migratórias (ZARCO, 2004, p. 65-69). A

\footnotetext{
${ }^{7}$ Assim como o projeto Post Scriptum: A Digital Archive ofOrdinaryWritings (Early Modern Portugal and Spain, dirigido pela professora Rita Marquilhas: http://ps.clul.ul.pt/en/index.php?action=home . Acesso em: 01/09/2021.

${ }^{8}$ Ver também a página: Memória Personal, http://www.memoriapersonal.eu/. Acesso em: 01/09/2021.

9 Ambas construídas com materiais pessoais conservados em mãos privadas ou em instâncias oficiais, segundo os casos. Outra mostra, TAILlEMITE, 2009.
} 
investigação realizada com as 15.000 cartas compiladas foi publicada no The Polish Peasant in Europe and America, em 5 volumes, entre 1918 e 1920, em que se incluiu a edição de 764 cartas (THOMAS, ZNANIECKI, 1918-1920).

Aos poucos, a brecha aberta por essa obra conduziu a outras operações de memória documental privada, sobretudo com a volta de Znaniecki à Polônia em 1921. Por sua iniciativa, em 20 de dezembro deste ano, o Instituto de Sociologia de Poznan convocou um concurso de "memórias do trabalho", ao que se seguiram outros semelhantes após a Segunda Guerra Mundial, 800 entre 1946 e 1972, que implicaram a participação de aproximadamente 250.000 poloneses (MARKIEWICZ-LAGNEAU, 1976, P.593-595).

Contemporaneamente ao trabalho de Thomas e Znaniecki, na primeira década do século XX, o lingüista austríaco Leo Spitzer, estudioso das línguas latinas, aproveitando seu trabalho como censor do Ministério da Guerra de seu país, levou a cabo uma recompilação de cartas de soldados italianos, prisioneiros da Primeira Guerra Mundial, que foram publicadas ao término desta (SPITZER, 1921) ${ }^{10}$. Com referência ao mesmo conflito, pouco depois, entre 1929 e 1934, Adolfo Omedeo reuniu outra antologia epistolar, mas com enfoques distintos. A partir de uma concepção idealista e patriótica da guerra, se interessou, especialmente, pelas cartas de oficiais e graduados militares, para ele as que melhor expressavam esses ideais. Como consequência, relegou a um apêndice as cartas dos soldados comuns, por considerá-las irrevalentes e banais: "E, no entanto, nada mais insignificante do que essas cartas: elas atestam apenas o mais banal instinto de conservação: nada têm a dizer ao historiador" (OMEDEO, 1934, p, 14) ${ }^{11}$.

Por outro lado, em 1937, fundou-se o Mass Observation Archive, atualmente depositado na biblioteca da Universidade de Sussex. A iniciativa partiu de três intelectuais - o antropólogo Tom Harrison, o jornalista e poeta Charles Madge e o artista e produtor de documentários Humphrey Jennings - cujo propósito era analisar a crise desses anos por meio das experiências de vida das pessoas comuns. Referindo-se fundamentalmente ao período 1937-1949, em 1981, iniciou uma nova fase em que adotou o mesmo procedimento etnográfico para os anos finais do século XX (SHERIDAN, 1991, 1993; MAC-CLANCY, 1995; COURAGE, 2012).

Valendo-se desses testemunhos, em boa parte interessados pela formação de acervos da identidade nacional, nos anos oitenta se experimentou outra onda influenciada pelo auge da história social e elaboração desta, contando com narrativas escritas pelas classes populares. A partir de uma perspectiva científica e social, se tratava, fundamentalmente, de atenuar algumas lacunas que poderiam afetar o patrimônio documental, sobretudo aquele produzido e conservado em mãos de particulares: recordações, diários íntimos, correspondências, livros de memórias ou agendas que alguns podiam guardar em velhos baús. Nesse contexto, foram abertos, na Itália, os três centros que melhor têm representado o fenômeno dos "arquivos da escritura popular": Archivio Diaristico Nazionale, em Pieve Santo Stefano (1984), ainda que, em sua evolução posterior, tenha se orientado a preservar textos autobiográficos em sentido amplo; Archivio della Scrittura Popolare, em Trento (1987); Archivio Ligure della Scrittura Popolare (1988), com sede na Universidade de Gênova, além de outras coleções conservadas em distintas sedes, sobretudo em museus e bibliotecas da Resistência (CASTILLO GÓMEZ, 2001).

10 Tradução italiana: Lettere di prigionieri di guerra italiani. 1915-1918, Milano, Il Saggiatore, 1976; reeditado em 2016, com estudos de Lorenzo Renzi, Antonio Gibelli, Luca Morlino e Silvia Albesano. Acerca desta obra e de outras produções lingüísticas de seu autor, ver Desideri, 2019. Em outra obra, Spitzer estudiu as metáforas usadas nas cartas dos prisioneiros italianos para falar sobre a fome, apesar do fato de que era proibido. Ver Spitzer, 1921, recentemente traduzido do italiano: Perifrasi del concetto di fame. La lingua segreta dei prigionieri italiani nella Grande guerra, Milano, il Saggiatore, 2019.

${ }^{11}$ Sobre esta compilaçao e do viés exposto por Omedeo, ver Caffarena, 2005, p. 180-181. 
Sua constituição foi paralela à fundação, em 1986, do Archivio Interregionale della Scrittura Popolare, que não era um lugar de concentração física de documentos, pois esse trabalho era desenvolvido pelos centros que acabo de referir, era um grupo de trabalho orientado a promover a recuperação de fontes em estudos interdisciplinares ${ }^{12}$. Posteriormente, em 1988, criou-se a Federazione degli Archivi della Scrittura Popolare com o objetivo de "contribuir para a conservação, a salvaguarda e o resgate de toda produção escrita de matriz popular (publicada e inédita), com a exclusão apenas de documentos escritos de natureza institucional (atas de Câmaras de Trabalho, de sindicatos, de partidos políticos, de grupos, etc)"13.

$\mathrm{Na}$ década dos anos noventa e primeiros anos do século XXI, o fator social cedeu protagonismo em favor do fazer autobiográfico, em consonância com o interesse que distintas disciplinas - História, Psicologia, Educação, Antropologia ou Literatura - mostraram sobre as escrituras de si, priorizadas no conjunto de escrituras privadas e ordinárias, segundo se observa no nome que se deu a algumas das associações e arquivos criados neste tempo: Association pour l'autobiographie et le patrimoine autobiographique (Ambérieu-en-Bugey, Francia, 1992), Archives de la vie privée (Carouge, Suiza, 1994), Association europeenne pour l'autobiographie (Carcassone, Francia, 1998), Deutsches Tagebucharchiv (Emmendingen, Alemanha, 1998), Finnish Academy for Autobiographis and Folk Art (Kärsämäki, Finlandia, 1999), Archives du Patrimoine Autobiographique-APA Bélgique (Bruxelles, 2003) e Association pour la conservation des Archives de la vie ordinaire (Neuchâtel, Suiza, 2003), (LEJEUNE, 1991; IUSO, 1997; ANTONELLI, IUSO, 2000; IUSO, 2001; EURICE, 2008-2009; BARBALATO, MINGELGRÜN, 2012).

$\mathrm{Na}$ Espanha, se bem que alguns dos centros que hoje participam dos objetivos que estou comentando existiam desde antes, como o Museu do Povo das Astúrias, fundado em 1968, sua definição como arquivos interessados na recuperação e conservação do patrimônio escrito das pessoas comuns se viu estimulada com a criação, em 2004, da Rede de Arquivos e Investigadores da Escritura Popular, cuja denominação reflete uma clara influência da experiência italiana (MONTEAGUDO ROBLEDO, 2008 -2009). Além dos investigadores registrados, esta rede é formada hoje por dezesseis centros ou acervos, alguns deles vinculados a instituições oficiais e outros não. Alguns têm um caráter genérico: Arxiu de la Memòria Popular (La Roca del Vallès, Bacelona), Archivo Bajo Duero de la Escritura Popular (atualmente depositado no Museo Etnográfico de Castilla y León, Zamora), Archivo de Escrituras Cotidianas (Universidad de Alcalá), Museo de la Escritura Popular (Terque, Almería) y Archivo de la Memoria Histórica de Canarias (Universidad de Las Palmas de Gran Canaria). Outros vêm se especializando em assuntos como a imigração: Muséu del Pueblu d'Asturies (Gijón), Arquivo da Emigración Galega (Santiago de Compostela), Centro de Estudios de la Emigración Castellana y Leonesa (Zamora) y Centro de Interpretación de la Emigración e Instrucción Pública (Boal, Asturias); o la cultura escolar: Centro Internacional de la Cultura Escolar (CEINCE) (Berlanga de Duero, Soria), Museo Pedagógico de la Universidad de Salamanca, em Zamora. Enfim, o fundo "Palabras en el tiempo", do Archivo de la Fundación Antonio Machado de Collioure está constituído por mensagens de tipos distintos - especialmente de admiração e afinidade política - e sobre diferentes suportes que se deixaram na tumba do poeta espanhol naquela localidade do sudoeste francês ou se

$12 \mathrm{O}$ documento, intitulado «Per un archivio interregionale della scrittura popolare», foi publicado em Materiali di Lavoro, 1-2, 1986, pp. 223-227 e nas revistas que se somaram à iniciativa: Movimento operaio e socialista, Rivista italiana di dialettologia, Venetica, La ricerca folklorica, I giorni cantati, Memoria, Fonti orali. Studi e ricerche. Véase también en AnTONELli Quinto, Scritture di confine. Guida all'Archivio della scrittura popolare, Trento, Museo Storico in Trento, 1999. pp. 16-20.

13 A proposta de estatuto, aprovada durante o segundo seminário sobre a escrita popular, celebrado em dezembro de 1988, foi publicado na recensão do mesmo: «Il secondo seminario nazionale dell'Archivio della scrittura popolare (Trento, 10-11 dicembre 1988)», Materiali di lavoro, 1-4, 1988, nuova serie, pp. 245-247. Pode ver-se: ANTONELLI, 1999, p. 30-32 (p. 30 para a citação). Sobre estes começos, ver também CASTELLI (1987). 
depositaram na caixa de correio que a citada fundação instalou nela nos anos oitenta do século passado (SIERRA BLAS, 2015, SIERRA BLAS, 2016; SIERRA BLAS, 2019) ${ }^{14}$.

Segundo se tem visto, a formação destes acervos, assim como dos atos de escritura das ocasiões que os geraram, responde, preferencialmente, à intervenção de associações e entidades muito diversas, o que, por si só, constitui um feito social digno de estudo (LAHIRE, 2004, p. 43). Em que pese seu caráter majoritariamente não institucional e inclusive antiinstitucional em certos casos, na opinião de Patrice Marcilloux, este tipo de arquivo não escapa a uma certa lógica de legitimação. Esta pode produzir-se pela apropriação de um espaço para o arquivo, até o ponto de encarnar a identidade do lugar, como acontece com Pieve Santo Stefano, a cittá del diario, ou pela implicação emotiva através da leitura dos manuscritos depositados neles ou mediante os concursos autobiográficos que alguns organizam, por exemplo, a Association pour l'autobiographieet le patrimoine autobiographique, el Archivio diaristico nazionale o el Arxiu de la Memòria Popular. Estes fatores levam ao dito autor a afirmar que "toda acumulação guardada em vida precisa de um reconhecimento para não ser algo em vão: é necessário um refúgio ao tesouro" (MARCILLOUX, 2013, p. 87)

\section{Escritas autobiográficas, cotidianas e populares}

Explicado o processo que deu origem a este conjunto de arquivos autobiográficos, da vida privada e da escrita popular cotidiana, focarei agora nos matizes das diferentes denominações, não sem antes fazê-lo sobre o termo "arquivo". Na pureza arquivística, é evidente que, na maior parte dos casos, tratam-se de coleções documentais que não comportam a definição canônica que podemos encontrar em manuais, dicionários e leis relacionadas com os arquivos. Assim, no vocabulário da terminologia arquivística, promovido pelo International Council on Archives, se contemplam três significados:

1. "Conjunto de documentos, quaisquer que sejam sua data, forma e suporte material, produzidos ou recebidos tanto por pessoa física ou jurídica, por serviço ou organismo público ou privado no exercício de sua atividade e que seja conservado por seu criador ou seus sucessores, por suas necessidades próprias, transmitidos à instituição de arquivos competente, em razão de seu valor arquivístico.

2. Instituição responsável de assistência, tratamento, inventário, conservação e comunicação de arquivos, dito também serviço de arquivos.

3. "Prédio ou parte de prédio onde são conservados ou comunicados os arquivos, dito também depósito de arquivos" (WALNE, 1988, p.22).

A primeira destas definições, que é a que mais interessa para o objeto deste trabalho, é basicamente a que inspirou as legislações sobre patrimônio histórico e arquivos de diferentes países. No caso da lei 16/1985 de Patrimônio Histórico Espanhol, o artigo 59 considera arquivos "os conjuntos orgânicos de documentos, ou o conjunto de vários documentos, reunidos pelas pessoas jurídicas públicas ou privadas, no exercício de suas atividades, a serviço de sua utilização para investigação, cultura, informação e gestão administrativa"15. Quer dizer, praticamente o mesmo que estabelece, por exemplo, a lei francesa de 3 de janeiro

\footnotetext{
${ }^{14}$ A admiração é compartilhada por outros escritos a «ídolos» como as mais de 140.000 cartas que foram enviadas a cantora italiana Gigliola Cinquetti, nos anos sessenta e setenta do século passado, desde todas as regiões da Itália e diferentes países estrangeiros. Ver: IUSO, ANTONELLI, 2007.

${ }^{15}$ Disponível em: https://www.boe.es/buscar/doc.php?id=BOE-A-1985-12534 . Acesso em: 01/09/2021.
} 
de 1979: "Conjunto de documentos, quaisquer que sejam sua data, forma e suporte material, produzidos ou recebidos tanto por pessoa física ou jurídica, por serviço ou organismo público ou privado, no exercício de sua atividade" $(\operatorname{art} .1)^{16}$.

A partir deste ponto de vista, os arquivos de escrita popular, autobiográficos ou de vida cotidiana, nem sempre podem ser considerados como acervos pessoais, uma vez que são geralmente constituídos por documentos muito heterogêneos e por numerosas peças soltas, juntos, certamente, a alguns legados pessoais ou familiares mais homogêneos. No entanto, entendo que, nestes casos, o rigor arquivístico não deveria ser uma condição imprescindível, visto que estamos falando de intervenções na recuperação e salvaguarda de um certo tipo de patrimônio escrito que respondem a outros propósitos e, normalmente, preenchem vazios não atendidos pelas pessoas e instituições que têm a responsabilidade de conservar, classificar e transmitir a memória escrita.

Em consequência, me parece mais relevante deter-me nos complementos do nome, começando pela designação "arquivos de escrita popular", que se vinculam expressamente com a experiência italiana. Foi ali que, ao final da década de setenta, iniciou-se uma linha de pesquisa sobre "alfabetização e cultura escrita", na qual participaram diferentes profissionais, como paleógrafos alla rovescia, isto é, de formações heterodoxas, como historiadores, lingüistas e antropólogos. Reuniu-se uma geração sólida teoricamente e combativa no âmbito acadêmico, da qual integraram pessoas como Armando Petrucci, Attilio Bartoli Langeli, Carlo Ginzburg, Giordio Raimondo Cardona e Franco Cardini, que, na época, chamaram a atenção sobre o estudo da escrita em sua dimensão social, incidindo expressamente no uso ativo e passivo dela por parte das classes populares ${ }^{17}$.

Nesse sentido, Armando Petrucci assinalou o interesse particular que tinha o estudo dos testemunhos gráficos produzidos pelas classes subalternas ou vinculados a elas, ao mesmo tempo em que afirmou a ambiguidade do termo "escrita popular"18, por várias razões: a) a dificuldade de atribuir o "uso de um determinado tipo de escritura de uma categoría precisa de classe social"; b) o fato de pertencer aos setores populares não significa ser excluído no passado, pelo menos individualmente, de "um certo grau de promoção social (basta pensar nos escravos "notários" do mundo romano); e c) a escrita empregada pelas classes subalternas não tem "características homogêneas, autônomas e, portanto, identificáveis" (PETRUCCI, 1979, p. 23-24). Como paleógrafo, sua reflexão centrou-se, fundamentalmente, no aspecto gráfico da escrita. Ao não observar características exclusivas das classes subalternas, o termo "escrita popular" lhe pareceu redutor e até inapropriado. No entanto, outros estudos têm desenvolvido uma perspectiva diacrônica, ou seja, considera-se uma série de características gráficas e linguísticas bastante comuns às "mãos inábeis", isto é, próprias das pessoas com uma insuficiente competência alfabética ou com uma prática de escrita inconstante (MARQUILHAS, 2000, p. 239-240) ${ }^{19}$.

A problemática do termo, assumida por aqueles que a impulsionaram, tem permitido que, frequentemente, se troque por escritas "da margem", da "fronteira" ou de "pessoas comuns" (ANTONELLI, 1999, p. 24-29; GIBELLI, 2002; CAFFARENA, 2016), e também por escritas "autobiográficas", "cotidianas" ou da "vida privada". Em alguns casos, se põe a

16 Disponível em: https://www.legifrance.gouv.fr/affichTexte.do?cidTexte=LEGITEXT000006068663. Acesso em: 01/09/2021.

${ }^{17}$ Alfabetismo e cultura scritta nella storia della società italiana, 1978. Ver também: BARTOLI LANGELI, 1978.

18 Este conceito foi empregado anteriormente por Charles Perrat ao destacar o papel desempenhado pela bastarda francesa, amplamente usada no campo documental, privado e livreiro durante a Baixa Idade Média. PERRAT, 1961, p. 606

19 Enquanto a persistência diacrônica das características gráficas: BARTOLI LANGELI, 2000; HANSBIANCHI, 2005; STEFFEN, THUn, ZAISER, 2018. o próprio Petrucci admitiu pouco depois que em determinadas circunstâncias as execuções gráficas mais elementares constituem "verdadeiramente a própria escrita popular" isto é, reservados para uso pelas classes subalternas da sociedade", Petrucci, 1979, p. 29. 
ênfase na condição social dos que escrevem, enquanto que, em outros, se dá preferência para a tipologia textual ou ao domínio de produção, se entendemos este, de acordo com Giorgio Raimondo Cardona, como "o conjunto de situações sociais regidas por regras de conduta" (CARDONA, 1987, p. 100).

As denominações que priorizam o caráter autobiográfico, evidentemente, são mais interclassistas, pois antepõem este aspecto à condição social do sujeito, por mais que, em determinados casos, se tenha focado nas classes populares. Sua difusão foi maior entre os estudiosos de prática literária, assim como entre aqueles que se interessam pelo seu potencial terapêutico ou resiliente, o que tem levado a falar de "arquivos que curam" 20 (CYRULNIK, 2008, p. 12-15; MARCILLOUX, 2013, p. 85). No princípio, a autobiografia foi entendida de forma restrita, como "o relato ou história em prosa que alguém realmente faz de sua (própria) existência, quando coloca a marca de sua própria vida (vida individual), particularmente a história de sua personalidade" (LEJEUNE, 1975, p.14) ${ }^{21}$. Posteriormente, o conceito prescindiu da condição introspectiva e passou a designar o conjunto de textos que falam do indivíduo, uns escritos em primeira pessoa e outros não.

Entre alguns historiadores, popularizou-se o conceito "egodocumentos", na realidade cunhado pelo holandês Jacques Presseren, na década de cinquenta, e desenvolvido mais tarde por seu conterrâneo Rudolf Dekker. Compreende tanto os textos que "escondem ou descobrem deliberada ou acidentalmente um ego" (PRESSER, 1969, p. 286, Cf. DEKKER, 2002, p. 14),), como aqueles nos quais "um autor escreve sobre seus próprios atos, pensamentos e sentimentos" (DEKKER, 1999, p. 255). Embora se trate de uma categoria não isenta de matizes e controvérsias, uma das suas principais vantagens está precisamente na plasticidade que oferece ao englobar modalidades textuais tão diversas, e, ao mesmo tempo, próximas, como são as autobiografias, memórias, diários, livros de família, crônicas pessoais, relatos de viagem e inclusive as ficções autobiográficas (DEKKER, 2002; AMELANG, 1998; AMELANG, 2005). Portanto, nem a expressão do eu devemos entendê-la como um código puramente introspectivo, nem o autor tem que escrever necessariamente por si mesmo. A esta necessidade, me parece conveniente acomodá-la também aos textos autobiográficos resultantes da delegação da escrita, ora pelo analfabetismo ou pela falta de habilidade do sujeito, ora por qualquer adversidade ou infortúnio, ora simplesmente porque se confia o ato de escrever a alguém próximo.

Mais centradas no domínio de produção da escrita são outras categorias de amplo eco na historiografia francesa, seja a tradicional "escrita de foro privado", amplamente usada em pesquisas de perfil histórico ${ }^{22}$, ou seja, na mais recente "escrita cotidiana" ou "ordinária", com um perfil mais antropológico (FABRE, 1993; FABRE, 1997). De acordo com Daniel Fabre, que foi seu principal impulsionador, as escritas comuns se opõem significativamente "ao conceituado universo de escritas que distinguem o desejo de fazer um bom trabalho à autêntica marca do autor, à consagração da impressão". Tratam-se, em sua opinião, de escritas alheias aos requerimentos da instituição literaria, associadas, em geral, a acontecimentos coletivos ou pessoais de certa intensidade ou à rotina das ocupações cotidianas:

${ }^{20}$ No filme Coming Home (2014), do diretor chinês Zhang Yimou, essa é a intenção que leva ao protagonista masculino, Lu Yanshi, a entregar uma caixa de cartas a sua esposa, Feng Wanyu, doente com uma amnésia psicógena, para ver se assim, consegue reconhecê-lo quando retorna para casa, após anos preso em um campo de trabalho durante a Revolução Cultural.

${ }^{21}$ Pouco aberta aos textos que não tiveram esse caráter introspectivo, o próprio autor revisou e matizou-a posteriormente. Ver: LEJEUNE, 2004; LEJEUNE, 2005.

${ }^{22}$ FOISIL, 1986; BARDET, RUGGIU, 2005; RUGGIU, 2007; BARDET, ARNOUL, RUGGIU, 2010; RUGGIU, 2013; BARDET, RUGGIU, 2014. 
Elas aspiram ao exercício escrupuloso do bom uso e à sacralização que, pouco ou muito, acompanha a distância literária há dois séculos. Depois, em especial, a maior parte destas escritas, associadas a momentos coletivos ou pessoais intensos e rotineiros, parecem destinadas a uma única função que as absorve e uniformiza, deixa vestígios. Elas não têm outro sentido, não têm outros efeitos. Testemunham tudo, na melhor das hipóteses, de competência que se torna evidente apenas quando não se tem mais (FABRE, 1993, p.11).

Considerando o mais importante desta definição, queria ressaltar a importância que Fabre atribuiu à autoria, para fins de fazer uma obra e, portanto, a consagração através da imprensa/impressão. Contudo, a difusão tipográfica é uma ambição própria daqueles que concebem a produção escrita como um ofício. Sobre isso, valem duas observações. De um lado, a legitimação impressa não tem operado com a mesma lógica em todos os momentos da história. E mais, em períodos como a Idade Moderna, a poesia e o teatro desfrutaram de uma ampla circulação manuscrita, sem que isso diminuísse a notoriedade dos autores. No outro extremo, na Época Contemporânea, em particular no século XX, são abundantes os diários e memórias correntes, inclusive das classes populares, que alcançaram o status impresso pelo seu valor testemunhal, antes que literário, sem que, por isso, deixem de ser escritas ordinárias, no sentido mais pleno da palavra. Entende-se que o prestígio da imprensa não pode ser um atributo para determinar o caráter ordinário ou não de um determinado escrito. É necessário diferenciar, segundo os textos e a vontade de seus autores e autoras, estabelecendo uma prudente distinção entre aqueles cujo sentido está no desejo de deixar um rastro e aqueles outros concebidos como literários e habitualmente concebidos para serem publicados, apesar do fato de que, na atualidade, esta condição teria que ser repensada, a partir dos novos horizontes que a internet está abrindo (CASELLAS I SERRA, 2014).

Retornando ao início desta discussão conceitual, se, nos arquivos autobiográficos, como disse Daniel Fabre, "a testemunha da história dá lugar ao explorador de intimidade" (FABRE, 1998, p.7), na escrita popular prevalece a condição social dos sujeitos. Sem necessidade de entendê-la de maneira rígida e apesar de suas interdições com o desenvolvimento da sociedade de massas ${ }^{23}$, algo que está sendo questionado à luz da atual crise (JONES, 2011; SIBLOT, CARTIER, COUTAN, MASCLET, 2015), tampouco parece que seja muito sugestivo aludir às diferentes desigualdades, dissolvendo-as em formulações literárias ou antropológicas menos comprometedoras. Se o fazemos, existe o risco de que a produção escrita das classes populares (ou das pessoas comuns) se torne invisível no magma das escritas cotidianas, de foro privado ou autobiográficas, com o qual renunciaremos ao projeto reivindicativo que amparou os primeiros movimentos nessa direção.

\section{Conclusão}

A aproximação que delineei nessas páginas da memória das classes subalternas tem se centrado expressamente na vertente escrita, mas é obvio que seu testemunho admite também registros sonoros, visuais e inclusive eletrônicos. Com isso, se abre todo um mundo ainda a explorar que é paralelo à substituição do papel pela tela como suporte de escritura, mas igualmente permanecem as incertezas da conservação digital.

Pensemos na natureza efêmera de certo tipo de mensagens (sms, WhatsApps, chats etc.), e na falta de arquivos e depósitos de correspondência eletrônica ou na rápida obsolescência dos distintos sistemas de armazenamento. Deixo apenas apontada essa questão, posto que

\footnotetext{
${ }^{23}$ Pertinentes, nesta direção, são as reflexões feitas por ELEY, NIELD, 2007.
} 
tampouco seja um terreno que eu me sinta confortável. Sinto-me mais apegado à tradição escrita que nos têm constituído como humanidade, desde o longínquo quarto milênio antes da nossa era até a atualidade. Para concluir, quero insistir na necessidade de buscar e conservar a produção escrita das classes subalternas por varias razões.

A primeira é fundamental porque considera o que foi guardado como ecos de muitas vozes que nem sempre têm merecido a suficiente atenção e, muito frequentemente, vêm sendo marginalizadas nas políticas públicas da memória documental. Inclusive quando estas têm sido mais sensíveis, o foco se projeta mais voltado para as instituições políticas, sindicais ou assistenciais que atuaram a favor das classes populares e dos membros destas. Sobre esse abandono, sobram mostras da celeridade com que atuam políticos e responsáveis de arquivos, quando se trata de resgatar do esquecimento os documentos relacionados com a história das elites e das instituições, incluídas as da classe operária, enquanto que não se tem igual diligência com a documentação relativa às pessoas comuns.

A segunda porque se trata de uma documentação sumamente frágil, mas que ainda se pode encontrar e conservar. Como dito, há anos, o militar antifascista Nuto Revelli (1977), um dos que mais fizeram na Itália por dignificar a memória dos vencidos, por mais que o campesinato tenha professado o "culto aos papéis", próprio das elites, nos 70, quando publicou O mundo dos perdedores. Testemunhos da vida camponesa, todavia eram muitos os arquivos familiares que poderiam ser encontrados em cada povoado em caixas de lata ou de papelão.

Tal situação ainda segue ocorrendo, de maneira que o resgate e preservação dessa documentação é também um ato de responsabilidade frente à marginalização sofrida durante séculos, inclusive um "dever de memoria". Não só por sua utilidade na hora de superar experiências traumáticas, senão também porque suturam as feridas sociais que provocam toda a construção da memória sensível. Porque consolidam a ideia do arquivo como um "reservatório da memória coletiva identificada, sobretudo, aos saberes e práticas das classes dominadas e dos grupos subalternos". Assim, manifestou-se, há pouco tempo, no texto da convocatória do Seminário Internacional "Arquivos dos comuns", celebrado em dezembro de 2015 no Museo Centro Nacional Reina Sofía de Madrid, aonde também se afirmava o seguinte:

refletir sobre como esses arquivos, que alimentam um patrimônio importante da memória, da experiência e da identidade coletivas, podem ser construídos, gestionados, conservados e abertos à cidadania e ao público em geral como um exercício de cultura cívica e democrática, com independência de critérios de responsabilidade nacional ou de disponibilidade de recursos econômicos para sua consulta, uso ou desfrute; e debater qual seria a possível implicação das instituições públicas para proteger este tipo de arquivos frente ao duplo perigo de sua privatização (por exemplo, das coleções de arte latinoamericana, fruto do trabalho de artistas individuais ou coletivos) ou sua invisibilização e abandono (por exemplo, a memória de lutas e acontecimentos sociais importantes e constitutivos da experiência do presente, mas marginalizados pelos modos de produção de discurso e memória do establishment midiático, acadêmico e institucional).

$\mathrm{O}$ aspecto crucial é, pois, a questão da memória pública produzida pelas atuais formas de conservação da ação social, que deixam fora do discurso dominante partes importantes não só da história em geral, mas também da experiência coletiva da mais estrita contemporaneidade. Pensamos que esta linha de investigação sobre o arquivo e a memória dos grupos subalternos e dominados introduz uma poderosa linha de reflexão em torno de novos direitos políticos e 
as novas características de uma esfera pública genuinamente democrática em um momento como o atual, que se encontra atravessado por um sentido de crises multifatoriais que afetam profundamente as formas de comportamento coletivo em nossas sociedades.

Arquivos do comum concentram estes debates e linhas de trabalho, já que se pensa o arquivo como motor de ativação política no presente, ao mesmo tempo que pretende definir dispositivos que não cancelem, nem efetivem as dinâmicas que procedem esses exercícios de conservação da memória ${ }^{24}$.

O historiador indiano Ranahit Guha, uma das vozes mais destacadas da corrente dos estudos subalternos, se mostra convencido de que "na prática da historiografia, inclusive os elitistas têm que representar seu papel, ainda que seja o de ensinar com exemplos negativos", daí que também proclamou sua convicção de que "a historiografia elitista deveria ser combatida" (GUHA, 2002, p. 40). Não apenas a historiografia, mas também as operações de memória sintetizadas nas políticas arquivísticas. E para ambos, entendo que podem ser fundamentais, tanto os arquivos da escritura popular como aqueles outros que se interessam expressamente pelos registros escritos, visuais, sonoros ou eletrônicos de indivíduos e grupos marginalizados, desde as mulheres, largamente preteridas como sujeitos de memória e arquivo, até as minorias étnicas e coloniais, os movimentos sociais de nosso tempo (MARCILLOUX, 2013, 13-48).

Não esqueçamos, parafraseando Schwartz y Cook, que o controle do arquivo comporta o controle da sociedade e, portanto, a capacidade de determinar os vencedores e os perdedores da história, ou seja, de privilegiar ou de marginalizar, podendo ser uma ferramenta de hegemonia ou de resistência (SHWARTZ; COOK, 2002, p. 4-13). Em nós mesmos, está a decisão a adotar a história como relato elaborado e contrastado aos acontecimentos, não deveria pautar-se no silêncio de umas vozes e no aplauso de outras. No mais, se a curto prazo a história pode ser dos vencedores, na longa temporalidade, como sustenta Reinhart Koselleck, os avanços de conhecimento da mesma se devem aos vencidos, pois são eles quem alimentam as transformações históricas (KOSELLECK, 2001, p. 83-92).

\section{Bibliografia}

AMELANG, James S. (org.), De la autobiografía a los ego-documentos: un fórum abierto, dossier monográfico de la revista Cultura escrita \& Sociedad, 1, 2005.

AMELANG, James S. The Flight of Icarus. Artisan Autobiography in Early Modern Europe. Stanford, California: Stanford UniversityPress, 1998.

ANTONELLI, Quinto e IUSO Anna (org.), Vite in archivio, Napoli: Ancora, 2000.

ANTONELLI, Quinto. Scritture di confine. Guida all'Archivio della scrittura popolare. Trento: Museo Storico in Trento, 1999.

24 Disponível em: http://www.museoreinasofia.es/actividades/archivos-comun. Acesso em: 01/09/2021. Ver também: PRIETO DEL CAMPO, Carlos. «Archivos del común o los commons del conocimiento, la información y la memoria, disponível em: http://www.internationaleonline.org/research/decolonising_practices/64_archivos_del_comun_o_los_commons_del_conocimien to_la_informacion_y_la_memoria. Acesso em 01/09/2021. 
ARTIÈRES, Philippe; LAÉ, Jean-François. Archives personnelles. Histoire, anthropologie et sociologie, Paris: Armand Collin, 2011. DOI https://doi.org/10.3917/arco.artie.2011.01

ASENSI, Manuel. La subalternidad borrosa. Un poco más de debate en torno a los subaternos. In SPIVAK, Gayatri Chakravorty, ¿Pueden hablar los subalternos?, op. cit., p. 9-39.

BARBALATO, Beatrice; MINGELGRÜN, Albert (orgs.). Télémaque: Archiver et interpréter les témoignages autobiographiques, Louvain-la-Neuve, Presses universitaires de Louvain, 2012.

BARDET, Jean-Pierre; ARNOUL, Elisabeth; RUGGIU, François-Joseph (org.), Les écrits du for privé en Europe. Enquêtes, Analyses, Publications. Bordeaux: Presses Universitaires de Bordeaux, 2010.

BARDET, Jean-Pierre; RUGGIU, François-Joseph (org.), Au plus près du secret des cœurs? Nouvelles lectures historiques des écrits du for privé en Europe du XVI e aux XVIII e siècle. Paris: Presses universitaires de Paris-Sorbonne, 2005.

BARDET, Jean-Pierre; RUGGIU, François-Joseph (org.). Les écrits du for privé en France. De la fin du Moyen âge à 1914. Paris: Éditions du Comité des travaux historiques et scientifiques, 2014.

BARTOLI LANGELI, Attilio La scrittura dell'italiano, Bologna: Il Mulino, 2000.

BARTOLI LANGELI, Attilio. Ancora su paleografia e storia della scrittura: a proposito di un convengo perugino, Scrittura e civiltà, II, 1978, p. 275-294.

BENEDETTI, Mario. El olvido está lleno de memoria. Madrid: Visor, 1997 (1ª ed., 1995).

BRECHT, Bertolt. Poemas y canciones [1960-1965], Madrid: Alianza Editorial, 1998.

CAFFARENA Fabio, Scritture non comuni. Una fonte per la storia contemporanea, Milano: Unicopli, 2016.

CAFFARENA, Fabio. Lettere dalla Grande Guerra. Scritture del quotidiano, monumenti della memoria, fonti per la storia: il caso italiano. Milano: Unicopli, 2005.

CARDONA, Giorgio Raimondo. Antropologia della scrittura, Torino, Loescher, 1987 $\left(1^{\mathrm{a}}\right.$ ed. 1981).

CASELLAS I SERRA, Lluís-Esteve; HERNÁNDEZ OLIVERA, Luis (orgs.), Ego archivo. Memorias personales en un mundo digital, monográfico de la revista Tabula, 17, 2014.

CASTELLI, Franco. Per un archivio della scrittura popolare: problemi, suggestioni, prospettive, Quaderno di storia contemporanea, 2, 1987, p. 55-65.

CASTILLO GÓMEZ, Antonio (coord.). La conquista del alfabeto. Escritura y clases populares, Gijón: Trea, 2002. 
CASTILlO GÓMEZ, Antonio. «Conjurando el olvido: la Red de Archivos e Investigadores de la Escritura Popular», in BARBALATO, Beatrice; MINGELGRÜN, Albert (orgs.), Télemaque, op. cit., p. 213-215.

CASTILLO GÓMEZ, Antonio. Entre la pluma y la pared. Una historia social de la escritura en los siglos de Oro, Madrid: Akal, 2006.

CASTILLO GÓMEZ, Antonio. Notas sobre escritura y memoria popular en Italia, Boletín de la Unidad de Estudios Biográficos, 5, 2001, p. 51-59.

COLLECTIF MAURICE FLORENCE, Archives de l'infamie, avec le texte de Michel Foucault, La vie des hommes infâmes, Paris: Éditions Les Presses ordinaires, 2009.

COURAGE, Fiona. Observing Britain by Mass Observation, in BARBALATO, Beatrice; MINGELGRÜN, Albert (orgs.), Télémaque, op. cit., p. 49-58.

CYRULNIK, Boris. Autobiographie d'un épouvantail. Paris: Odile Jacob, 2008.

DAVIS, Natalie Zemon, Fiction in the Archives: Pardon Tales and their Tellers in Sixteenth Century France, Stanford, California: Stanford University Press, 1987.

DEKKER, Rudolf (org.). Egodocuments and History: Autobiographical Writing in its Social Context since the Middle Ages. Hilversum: Verloren; Rotterdam: Faculty of History and Art Studies, Erasmus University Rotterdam, 2002.

DEKKER, Rudolf. Egodocuments in the Netherlands from the Sixteenth to the Nineteenth Century. In: GRIFFEY, Erin (org.), Envisioning Self and Status: Self-Representation in the Low Countries 1400-1700. Hull: Association for Low Countries Studies in Great Britain and Ireland, 1999. p. 255-285.

DEKKER, Rufolf. Jacques Presser's Heritage: Egodocuments in teh Study of History, Memoria y Civilización, 5, 2002, p.13-37.

DEMETRIO, Duccio. Raccontarsi, Milano: Raffaello Cortina Editore, 1995.

DESIDERI, Paola; D’ANGELO, Mariapia. «La voce della Grande Guerra: le lettere dei prigionieri italiani raccolte da Leo Spitzer», Linguistica, LVIII/1, 2019.p. 271-282.

DUTRAY-LECOIN, Élise; MUZERELLE, Danielle. La Bastille ou "l'enfer des vivants" à travers les archives de la Bastille, Paris: Bibliothèque Nationale de France, 2010.

EDLUND, Anne-Catrine; ASHPLANT, Timothy G.; KUISMIN Anna (org.), Reading and Writing from Below: Exploring the Margins of Modernity, Umeå: Umeå University \& The Royal Skyttean Society, 2016.

ELEY, Geoff; NIELD, Keith. The Future of Class in History. What's left of the Social. Ann Arbor, MI: University of Michigan, 2007. 
EURICE, Francine (org.), La réception des textes dans les archives du patrimoine autobiographique, monográfico de Degrés. Revue de Synthèse à orientationsémiologique, $\mathrm{n}^{\circ}$ 136-137, hiver 20008-printemps 2009.

FABRE Daniel (org.), Par écrit. Ethnologie des écritures quotidiennes, Paris: Éditions de la Maison des sciences de l'homme, 1997. DOI https://doi.org/10.4000/books.editionsmsh.3949

FABRE, Daniel (org.). Écritures ordinaire, Paris: P.O.L.-Centre Georges Pompidou, 1993.

FABRE, Daniel. L'Europa autobiografica, Primapersona. Percorsiautobiografici, 1, 1998. p.6-7.

FARGE, Arlette Effusion et tourment. Le récit des corps. Histoire du peuple au XVIII siècle, Paris: Odile Jacob, 2007.

FARGE, Arlette Essai pour une histoire des voix au dix-huitième siècle, Paris: Bayard, 2009.

FARGE, Arlette La vie fragile : Violence, pouvoirs et solidarités à Paris au XVIII siècle, Paris : Hachette, 1986.

FARGE, Arlette Le Bracelet de parchemin. L'écrit sur soi au XVII' siècle, Paris: Bayard, 2003.

FARGE, Arlette, Vivre dans la rue à Paris au XVIII siècle, Paris: Gallimard, 1979. DOI: https://doi.org/10.3917.dec.farge.2019.01

FARGE, Arlette. Vies oubliées: Au coeur du XVIII siècle, Paris, La Découverte, 2019.

FARGE, Arlette. La atracción del archivo. (1989) Valencia: Edicions Alfons el Magnànim, 1991.

FARGE, Arlette; FOUCAULT, Michel. Le désordre des familles. Lettres de cachet des Archives de la Bastille, Xviiie Siècle [1982], Paris: Gallimard, 2014.

FOISIL, Madeleine, «L'écriture du for privé». In: Philippe Ariès et Georges Duby (org.), Histoire de la vie privé, vol. III. De la Renaissance aux Lumières. CHARTIER, Roger (org.). París: Seuil, 1986. p.331-369.

FOUCAULT, Michel. La vie des hommes infâmes, Les Cahiers du chemin, $\mathrm{n}^{\circ}$ 29, 15 janvier 1977, p. 12-29.

GALLEGO DOMÍNGUEZ, Olga. Manual de archivos familiares, Madrid, ANABAD, 1993.

GIBELLI, Antonio. Introduzione. Scritture e storie di gente comune. In CONTI, Piero; FRANCHINI, Giuliana; GIBELLI, Antonio (org.), Storie di gente comune nell'Archivio Ligure della Scrittura Popolare, Genova: Università degli studi di Genova: Dipartimento di Storia Moderna e Contemporanea-Editrice Impressioni Grafiche, 2002.

GRAMSCI, Antonio. Quaderni del carcere, 3, Quaderni 12-29, edição crírica do Instituto Gramsci a cargo de Valentino Gerratana, Torino: Einaudi, 1975.

GUHA, Ranahit. Las voces de la historia y otros estudios subalternos [1982, 1983 e 1996], Barcelona: Crítica, 2002. 
HANS-BIANCHI, Barbara. La competenza scrittoria mediale. Studi sulla scrittura popolare. Tübingen: Max Niemeyer Verlag, 2005.

HOBSBAWM, Eric J.; RUDÉ. Georges. Capitain Swing, New York: Pantheon Books, 1968.

HOBSBAWM, Eric. History from below: studies in popular protest and popular ideology in honour of George Rudé, ed. Frederick Krantz, Montréal - Québec, Concordia University, 1985.

IL SECONDO SEMINARIO NAZIONALE DELL'ARCHIVIO DELLA SCRITTURA POPOLARE (Trento, 10-11 dicembre 1988), Materiali di lavoro, 1-4, 1988, nuova serie, p.245-247.

IUSO, Anna. Les archives du moi ou la passion autobiographique, Terrain, $\mathrm{n}^{\circ} 28,1997$. p.125-138, DOI: https://doi.org/10.4000/terrain.3178

IUSO, Anna. Europa autobiographica, Genesis, vol. 16, $\mathrm{n}^{\circ}$ 1, 2001, p.220-231, DOI: https://doi.org/10.3406/item.2001.1191

JANÉ, Oscar; POUJADE, Patrice (org.). Memòria personal. Construcció i projecció en primera persona a l'època moderna, Madrid: Casa de Velázquez, 2015.

JONES, Owen. Chavs: The Demonization of the Working Class, London: Verso Books, 2011.

KOSELLECK, Reinhart. Los estratos del tiempo: estudios sobre la historia. Barcelona: Paidós, 2001.

LAHIRE, Bernard. Sociología y autobiografia, Revista de Antropología Social, 13, 2004.

LE GOFF, Jacques. Documento/ Monumento. In ID: El orden de la memoria. El tiempo como imaginario [1982], Barcelona, Paidós, 1991, p. 227-239.

LEJEUNE, Philippe (org.), Archives autobiographiques, monográfico de Cahiers de Sémiotique Textuelle, $\mathrm{n}^{\circ}$ 20, 1991.

LEJEUNE, Philippe. El pacto autobiográfico, 25 años después. In FERNÁNDEZ PRIETO, Celia; HERMOSILLA ÁLVAREZM Ma . Ángeles (orgs.), with collaboration of Anna Caballé, Autobiografía en España: un balance. Actas del Congreso Internacional celebrado en la Facultad de Filosofía y Letras de Córdoba del 25 al 27 de octubre de 2001, Madrid: Visor Libros, 2004, p. 159-172.

LEJEUNE, Philippe. Le pacte autobiographique, Paris: Seuil, 1975.

LEJEUNE, Signes de vie (Le pacte autobiographique, 2), Paris: Seuil, 2005.

LIGUORI, Guido. Tre accezioni di subalterno in Gramsci. Critica marxista, 6 (giugno 2011), pp. 33-41; e Id., Classi subalterne, marginali e classi subalterne fondamentali in Gramsci», Critica marxista, 4 (settembre 2015), p. 41-48.

LYONS, Martyn (org.), Ordinary Writing, Personal Narratives: Writing Practices in the 19th and Early 20th-Century Europe. Bern: Peter Lang, 2007. 
LYONS, Martyn. The Writing Culture of Ordinary People in Europe, c. 1860-1920. Cambridge: Cambridge University Press, 2013.

MAC-CLANCY, Jeremy. Brief-encounter: the meeting, in Mass-Observation, of British surrealism and popular anthropology, Man (N.S.), n 1, 1995, p. 495-512.

MACÍAS, Isabelo; MORALES PADRÓN, Francisco. Cartas desde América, 1700-1800, Sevilla, Junta de Andalucía, Consejería de Cultura y Medio Ambiente, 1991.

MANDINGORRA LLAVATA, Ma. Luz. Conservar las escrituras privadas, configurar las identidades, Valencia, Publicaciones de la Universitat de València, Seminari Internacional d'Estudis sobre la Cultura Escrita, 2000.

MARCILLOUX, Patrice. Les ego-archives. Traces documentaires et recherche de soi, Rennes: Presses universitaires de Rennes, 2013. DOI: https://doi.org.10.4000/books.pur.117242

MARKIEWICZ-LAGNEAU, Janina. L'autobiographie Pologne ou de l'usage social d'une technique sociologique, Revue française de sociologie, vol. 17, $\mathrm{n}^{\mathrm{o}}$ 4, 1976, p. 591-613.

MARQUILHAS, Rita. A Faculdade das Letras. Leitura e escrita em Portugal no século XVII. Lisboa: Imprensa Nacional-Casa da Moeda, 2000.

MEZZADRA, Sandro. Introducción. IN ID (org.). Estudios postcoloniales. Ensayos fundamentales, Madrid: Traficantes de sueños, 2008, p. 15-31.

MONTEAGUDO ROBLEDO, José Ignacio, Los archivos españoles de la escritura popular y la autobiografía, In: MEURICE, Francine (ed.), La réception des textes, op. cit., p. 1-9.

OMEDEO, Adolfo. Momenti della vita di guerra. Dai diari e dalle lettere dei caduti, RomaBari: Laterza, 1934.

OTTE, Enrique. Cartas privadas de emigrantes a Indias, 1540-1616, Sevilla: Junta de Andalucía, Consejería de Cultura, 1976.

PETRUCCI, Armando, Prima lezione di paleografía. Roma-Bari, Laterza, 2002.

PETRUCCI, Armando. Funzione della scrittura e terminologia paleografica. IN: Palaeographica, Diplomatica et Archivistica. Studi in onore di Giulio Battelli, Roma: Edizioni di Storia e Letteratura, 1979, vol. I, p. 3-30.

PETRUCCI, Armando. Per la storia dell'alfabetismo e della cultura scritta: metodi-materialiquesiti, in Alfabetismo e cultura scritta nella storia della società italiana. op.cit., p.33-47.

PETRUCCI, Armando. Per un archivio interregionale della scrittura popolare, Materiali di Lavoro, 1-2, 1986, p.223-227.

PETRUCCI, Armando. Scritture della memoria e memorie dello scritto. De l'ordine degli oggetti scritti all disordine della scrittura virtuale, Parolechiave, 9, 1995, p. 83-92. 
PIEDRAS MONROY, Pedro Andrés. Sobre Can the Subalterns's Speak de Gayatri Spivak», https://www.academia.edu/9687318/Sobre_Can_the_Subaltern_Speak_de_Gayatri_Spivak. Acesso em 01/09/2021.

PONS ALÓS, Vicente. Los archivos familiares: realidad y prospectiva desde la óptica del historiador de los archivos. In: MARTíNEZ, Rosa Ma. Blasco (coord.), I Simposium: Los archivos familiares en España. Estado de la cuestión, Santander, Asociación para la Defensa del Patrimonio Bibliográfico y Documental de Cantabria, 1996. p.43-94.

PRESSER, Jacques. Clio kijkt door het sleutelgat. In: PRESSER, Jacques. Uit het wer van J. Presser, Amsterdam: Athenaeum-Polaken Van Gennep, 1969, p.283-295.

PRIETO DEL CAMPO, Carlos. Archivos del común o los commons del conocimiento, la información y la memoria, http://www.internationaleonline.org/research/decolonising _ practices/64_archivos_del_comun_o_los_commons_del_conocimiento_la_informacion_y_la_ memoria. Acesso em 01/09/2021.

REVELLI, Nuto. Il mondo dei vinti. Testimonianze di vita contadina, Torino: Einaudi, 1977.

RUGGIU, François-Joseph (éd./dir.), The Uses of First Person Writin. Africa, America, Asia, Europe / Les usages des écrits du for privé. Afrique, Amérique, Asie, Europe. Bruxelles: Peter Lang, 2013.

RUGGIU, François-Joseph. Écrits du for privé. In: FIGEAC, Michel (org.), L'ancienne France au quotidien: la vie et les choses de la vie sous l'Ancien Régime. Paris: Armand Colin, 2007, p.167-170.

SÁNCHEZ RUBIO, Rocío; TESTÓN NÚÑ̃Z, Isabel. El hilo que une. Las relaciones epistolares en el Viejo y el Nuevo Mundo (siglos XVI-XVIII), Cáceres/Mérida: Universidad de Extremadura/Editora Regional de Extremadura, 1989.

SCHWARTZ, Joan M.; COOK, Terry. Archives, Records, and Power: The Making of Modern Memory, Archival Science, vol. 2, n 1-2, 2002.

SHERIDAN, Dorothy. Mass-Observation: des "capsules" de vie quotiedienne, Cahiers de sémiotique textuelle, 20, 1991, pp. 75-85.

SIBLOT, Yasmine; CARTIER Marie; COUTANT, Isabelle; MASCLET, Olivier; RENAHY, Nicolas. Sociologie des classes populaires contemporaines, Paris: Armand Colin, 2015.

SIERRA BLAS, Verónica. La boîte aux lettres d'Antonio Machado. In: BERTHERAT, Bruno (dir.). Les sources du funéraire en France á l'époque contemporaine, Avignon: Éditions Universitaires d'Avignon, 2015.

SIERRA BLAS, Verónica. Palabras en el tiempo. El archivo vivo de Antonio Machado en Collioure. IN: Actas del III Aula Juan de Mairena: Machado, el exilio español (Segovia, 1114 de noviembre de 2015), Segovia: Ayuntamiento de Segovia, 2016, p. 35-55.

SIERRA BLAS, Verónica. Palabras huérfanas. Los niños y la Guerra Civil, Madrid: Taurus, 1989. 
SIERRA BLAS, Verónica. Un dialogue qui jamais ne s'interrompt: le boîte aux lettres d'Antonio Machado à Collioure. IN: Collioure... les jours bleus d'Antonio Machado / los días azules de Antonio Machado, Canet: Editions Trabucaire, Fondation Antonio Machado de Collioure, 2019, p. 100-107.

SIERRA BLAS, Verónica: Cartas presas. La correspondencia carcelaria en la Guerra Civil y el Franquismo, Madrid: Marcial Pons, 2016.

SPITZER, Leo. Italienische Kriegsgefangene briefe. Materialien zu einer Charakteristik der volkstümlichen italienischen Korrespondenz, Bonn: Hanstein, 1921. Traducción italiana: Lettere di prigionieri di guerra italiani. 1915-1918, Tradução italiana: Milano: Il Saggiatore, 1976.

SPIVAK, Gayatri Chakravorty, ¿Pueden hablar los subalternos?, (1999). Barcelona: Museu d'Arte Contemporani, 2009.

STEFFEN, Joachim; THUN, Harald; ZAISER, Rainer (org.), Classes populaires, scripturalité, et histoire de la langue. Un bilan interdisciplinaire. Kiel: Westensee-Verlag, 2018.

TAILLEMITE, Hélène. lettres du bagne: les correspondances privées conservées par l'administration pénitentiaire coloniale dans les dossiers individuels des condamnés aux bagnes de Guyane et de Nouvelle-Calédonie, La Gazette des Archives, 214/2, 2009, p. 53-67.

THOMAS, William J.; ZNANIECKI, Florian. The Polish peasant in Europe and America, Boston: Richard G. Baldger, 1918-1920, 5 vols.

THOMPSON, Edward P. History from Below, The Times Literary Supplement, 7 April 1966, pp.279-280.

THOMPSON, Edward P. The Crime of Anonymity. In: HAY, Douglas; LINEBAUGH, Peter; RULE, John G.; THOMPSON, E. P.; WINSLOW, Cal, Albion's fatal tree: crime and society in eighteenth-century England, Harmondsworth: Penguin, 1977, p. 255-308.

THOMPSON, Paul. La historia oral y el historiador, Debats, $\mathrm{n}^{\circ}$ 10, dez. 1984, p.52-56.

TORRES I SANS, Xavier. Els Llibres de familia de pagès. Memòries de pagès, memòries de mas (segles XVI-XVIII). Girona: CCG Edicions, 2000.

VINCENT, David. The Rise of Mass Literacy: Reading and Writing in Modern Europe, Cambridge, Polity Press, 2000.

WALNE, Peter (org.). Dictionary of Archival Terminology / Dictionnaire de TerminologieArchivistique. English and French with equivalents in Dutch, German, Italian,

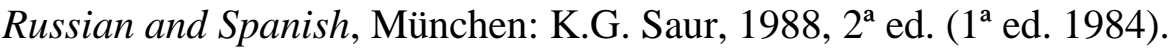

ZARCO, Juan. Estudio introductorio, In. THOMAS, William I.; ZNANIECKI, Florian, El campesino polaco en Europa y América, Madrid: op. cit., p. 21-90. Acesso em 01/09/2021. 